\title{
A COMPARISON OF METHODS USED FOR THE CALIBRATION OF RADIOCARBON DATES
}

\author{
T C AITCHISON*, MORVEN LEESE**, D J MICHCZYNSKA ${ }^{\dagger}$ \\ W G MOOK ${ }^{\ddagger}$, R L OTLET $^{\S}$, B S OTTAWAY $^{\#}$, M F PAZDUR $^{\dagger}$ \\ J VAN DER PLICHT ${ }^{\ddagger}$, P J REIMER $^{\pi}$, S W ROBINSON ${ }^{\#}$ \\ E M SCOTT* $^{*}$, MINZE STUIVER ${ }^{\pi}$ and BERNHARD WENINGER ${ }^{\circledR}$
}

\begin{abstract}
Current calibration methods for single and replicate ${ }^{14} \mathrm{C}$ dates are compared. Various forms of tabular and graphic output are discussed. Results from all the methods show reasonable agreement but further methodological development and improvements in computer output are required. Comparison of existing techniques for a series of non-contemporaneous dates showed less agreement amongst participants on this issue. We recommend that calibrated dates should be presented as a combination of graphs and ranges, in preference to mean and standard deviation.
\end{abstract}

\section{INTRODUCTION}

Three automatic calibration methods for ${ }^{14} \mathrm{C}$ dates were presented at the 2nd international symposium, Archaeology and ${ }^{14} \mathrm{C}$, held in Groningen, 1987 (van der Plicht, Mook \& Hasper; Michczynska, Pazdur \& Walanus; Warner, in press). Two automatic methods for calibration had already been suggested (Otlet, pers commun; Robinson, 1986) during the 12 th international ${ }^{19} \mathrm{C}$ conference in Trondheim in 1985 . There is now the widely distributed program, CALIB, for ${ }^{14} \mathrm{C}$ age calibration (Stuiver \& Reimer, 1986). Finally, Aitchison, Ottaway and Scott (in press) suggested an extension of the quartile interval method, dealing with groups of ${ }^{14} \mathrm{C}$ dates and their subsequent calibration. It is important that these various methods should be compared and contrasted.

\section{THE DATA}

It was suggested at Groningen to bring together these methods and compare them on the same data. The resultant sets sent out by B S Ottaway (Table 1, Questionnaire Qn 2) consisted of:

Data Set A: Six single dates, A1-A6, from different laboratories with different errors, dating separate events and spanning the period, 8th to 2nd millennia BP;

Data Set B: Four groups of ${ }^{14} \mathrm{C}$ dates (B1-B4) from different archaeological cultures. This suite is assumed to date the most active period of each culture, thus providing information on the duration of culture.

\footnotetext{
* Department of Statistics, University of Glasgow, Glasgow G12 8QW, UK

** Research Laboratory, British Museum, London, UK

$\dagger$ Radiocarbon Laboratory, Institute of Physics, Silesian Technical University, Krzywoustego 2, 44-100 Gliwice, Poland

₹ Centrum v Isotopen Onderzoek, Westersingel 34, 9718 CM Groningen, The Netherlands

Isotope Measurements Laboratory, Harwell, UK Atomic Energy Authority, Oxfordshire OX11 ORA, UK

\# Department of Archaeological Sciences, University of Hi adford, Bradford, BD7 1DP, UK

$\pi$ Department of Geological Sciences \& Quaternary Research Center, University of Washington, Seattle, Washington 98195

* US Geological Survey, Mail Stop 937, 345 Middlefield Road, Menlo Park, California, 94025

@ Institut für Ur- und Frühgeschichte, Universität Frankfurt, West Germany
} 
Data Set C: One set of replicate estimates (C1) ie, the same material dated by different laboratories and two sets of result from homogenized replicate samples $(\mathrm{C} 2.1 \& \mathrm{C} 2.2)$, from one laboratory, ie, counting replicates.

The eight groups participating in this study (Aitchison, Ottaway \& Scott; Leese; Otlet; Pazdur; van der Plicht, Mook \& Hasper; Robinson; Stuiver \& Reimer; Weninger) subjected the data sets to various calibration routines and completed a questionnaire, on practical details of the methods used.

TABLE 1

The three data groups for the calibration comparison

Data Set A: Single ${ }^{14} \mathrm{C}$ Dates

\begin{tabular}{|c|c|c|c|c|c|}
\hline Sample no. & $\begin{array}{l}\text { Date } \\
\text { (BP) }\end{array}$ & \pm & Site & Context & Ref \\
\hline IRPA-520 & 7030 & 80 & Drie Grachten 7 & Peat & $\mathrm{R}, 1986,28(1): 71$ \\
\hline Gif-2749 & 5900 & 140 & Port Leucate P.2 & Charcoal & $R, 1986,28(1): 20$ \\
\hline GrN-6483 & 4790 & 40 & Niederwil & Carbonized grain & $\begin{array}{l}\text { Lanting \& Mook, } \\
1977: 63\end{array}$ \\
\hline H-2123/1538 & 3745 & 60 & Dornburg & & $\mathrm{R}, 1970,12(2): 400$ \\
\hline GrN-7457 & 2480 & 35 & Texel-Den Burg & Mollusks & $\begin{array}{l}\text { Lanting \& Mook, } \\
1977: 151\end{array}$ \\
\hline BM-372 & 1598 & 70 & $\begin{array}{l}\text { Moerzeke-Marie } \\
\text { Kerke }\end{array}$ & Carved wood & $\begin{array}{l}\text { Lanting \& Mook, } \\
\text { 1977:196 }\end{array}$ \\
\hline
\end{tabular}

Data Set B: Groups of ${ }^{14} C$ Dates

\begin{tabular}{|c|c|c|c|c|c|}
\hline \multicolumn{2}{|c|}{$\begin{array}{l}\text { Group B1 } \\
\text { Michelsberg II culture } \\
\text { Material from several sites }\end{array}$} & (Lanting \& Mool & 1977, p 60-61) & \multicolumn{2}{|c|}{$\begin{array}{l}\text { Group B2 } \\
\text { Michelsberg III culture } \\
\text { Material from } 1 \text { site }\end{array}$} \\
\hline Sample no. & $\begin{array}{l}\text { Date } \\
\text { (BP) }\end{array}$ & \pm & Sample no. & $\begin{array}{c}\text { Date } \\
\text { (BP) }\end{array}$ & \pm \\
\hline KN I-663 & 5440 & 85 & KN I-306 & 5260 & 40 \\
\hline KN I-664 & 5490 & 95 & KN I-311 & 5210 & 40 \\
\hline KN I-418 & 5270 & 40 & $B \ln -54$ & 5140 & 80 \\
\hline KN I-419 & 5080 & 50 & $\mathrm{~B} \ln -70$ & 5240 & 100 \\
\hline KN I-773 & 5280 & 85 & Bln-71 & 5200 & 100 \\
\hline KN I-574 & 5480 & 105 & H-61/149 & 5140 & 130 \\
\hline KN I-720 & 5400 & 60 & $\mathrm{H}-125 / 107$ & 5200 & 200 \\
\hline KN I-722 & 5250 & 60 & KN I-304 & 5190 & 60 \\
\hline KN I-724 & 5050 & 85 & KN I-305 & 5160 & 60 \\
\hline GrN-6345 & 4965 & 40 & & & \\
\hline
\end{tabular}


Table 1 (continued)

\begin{tabular}{|c|c|c|c|c|c|}
\hline \multicolumn{3}{|c|}{$\begin{array}{l}\text { Group B3 - Pfyn culture } \\
\text { Material from } 3 \text { sites } \\
\text { (Lanting \& Mook, 1977: 62-63) }\end{array}$} & \multicolumn{3}{|c|}{$\begin{array}{l}\text { Group B4-Cham culture } \\
\text { Material from } 3 \text { sites } \\
\text { (Ottaway, (ms) 1986) }\end{array}$} \\
\hline Sample no. & $\begin{array}{l}\text { Date } \\
\text { (BP) }\end{array}$ & \pm & Sample no. & $\begin{array}{c}\text { Date } \\
\text { (BP) }\end{array}$ & \pm \\
\hline GrN-241 & 4735 & 135 & GrN-5732 & 4220 & 55 \\
\hline LJ-1279 & 4938 & 40 & GrN-6425 & 4340 & 40 \\
\hline LJ-1265 & 4982 & 40 & GrN-7159 & 3885 & 40 \\
\hline B-45 & 4780 & 130 & GrN-7556 & 4430 & 45 \\
\hline GrN-5957 & 5020 & 40 & GrN-8689 & 4305 & 35 \\
\hline GrN-5958 & 4965 & 40 & H-7415/7442 & 4350 & 40 \\
\hline GrN-4202 & 4750 & 60 & H-7415/7443 & 4170 & 70 \\
\hline GrN-4203 & 4990 & 60 & UB-2551 & 4285 & 85 \\
\hline GrN-4204 & 4750 & 60 & GrN-12561 & 4255 & 40 \\
\hline GrN-6482 & 4915 & 40 & GrN-12562 & 4290 & 45 \\
\hline GrN-6483 & 4790 & 40 & GrN-12563 & 4150 & 60 \\
\hline GrN-6484 & 4765 & 40 & GrN-12564 & 4210 & 60 \\
\hline GrN-6485 & 4800 & 40 & GrN-12699 & 4510 & 30 \\
\hline GrN-6486 & 4755 & 40 & GrN-12700 & 4225 & 30 \\
\hline GrN-7179 & 4875 & 50 & GrN-12701 & 4280 & 35 \\
\hline GrN-7090 & 4980 & 70 & GrN-12702 & 4385 & 35 \\
\hline B-44 & 4690 & 180 & GrN-14426 & 4420 & 35 \\
\hline \multirow{3}{*}{\multicolumn{3}{|c|}{$\begin{array}{l}\text { Group } C 1-\text { Results on identical } \\
\text { sample each from a different } \\
\text { laboratory (ISG, 1982) }\end{array}$}} & GrN-14427 & 4245 & 50 \\
\hline & & & GrN-14428 & 4500 & 80 \\
\hline & & & GrN-14429 & 4310 & 60 \\
\hline $\begin{array}{l}\text { Date } \\
\text { (BP) }\end{array}$ & \multicolumn{2}{|c|}{ \pm} & \multicolumn{3}{|c|}{$\begin{array}{l}\text { Group } C 2 \text { - Results from homogenized } \\
\text { replicate samples (counting replicates) } \\
\text { (Scott } \text { et al, 1983) }\end{array}$} \\
\hline 5110 & \multicolumn{2}{|c|}{50} & \multirow{3}{*}{$\begin{array}{l}\text { Date } \\
\text { (BP) }\end{array}$} & \multirow{3}{*}{\multicolumn{2}{|c|}{ \pm}} \\
\hline 4930 & \multirow{2}{*}{\multicolumn{2}{|c|}{$\begin{array}{l}50 \\
48\end{array}$}} & & & \\
\hline 5012 & & & & & \\
\hline 5106 & \multicolumn{2}{|c|}{31} & 5057 & \multicolumn{2}{|l|}{40} \\
\hline 5115 & \multicolumn{2}{|c|}{65} & 5167 & \multicolumn{2}{|l|}{40} \\
\hline 5110 & \multicolumn{2}{|c|}{60} & 5152 & \multicolumn{2}{|r|}{ C2 Batch 1} \\
\hline 5000 & \multicolumn{2}{|c|}{60} & 5085 & \multicolumn{2}{|l|}{50} \\
\hline 5138 & \multicolumn{2}{|c|}{19} & 5242 & \multicolumn{2}{|l|}{71} \\
\hline 5112 & \multicolumn{2}{|c|}{12} & & & \\
\hline 5050 & \multicolumn{2}{|c|}{90} & 5003 & \multicolumn{2}{|l|}{56} \\
\hline 5175 & \multicolumn{2}{|c|}{60} & 5169 & \multicolumn{2}{|l|}{57} \\
\hline 5027 & \multicolumn{2}{|c|}{36} & 5170 & \multicolumn{2}{|r|}{ C2 Batch 2} \\
\hline 5160 & 70 & & 4970 & 68 & \\
\hline 5130 & 90 & & 5314 & 64 & \\
\hline 4907 & 37 & & & & \\
\hline 5223 & 51 & & & & \\
\hline 4940 & 80 & & & & \\
\hline 5030 & 90 & & & & \\
\hline
\end{tabular}




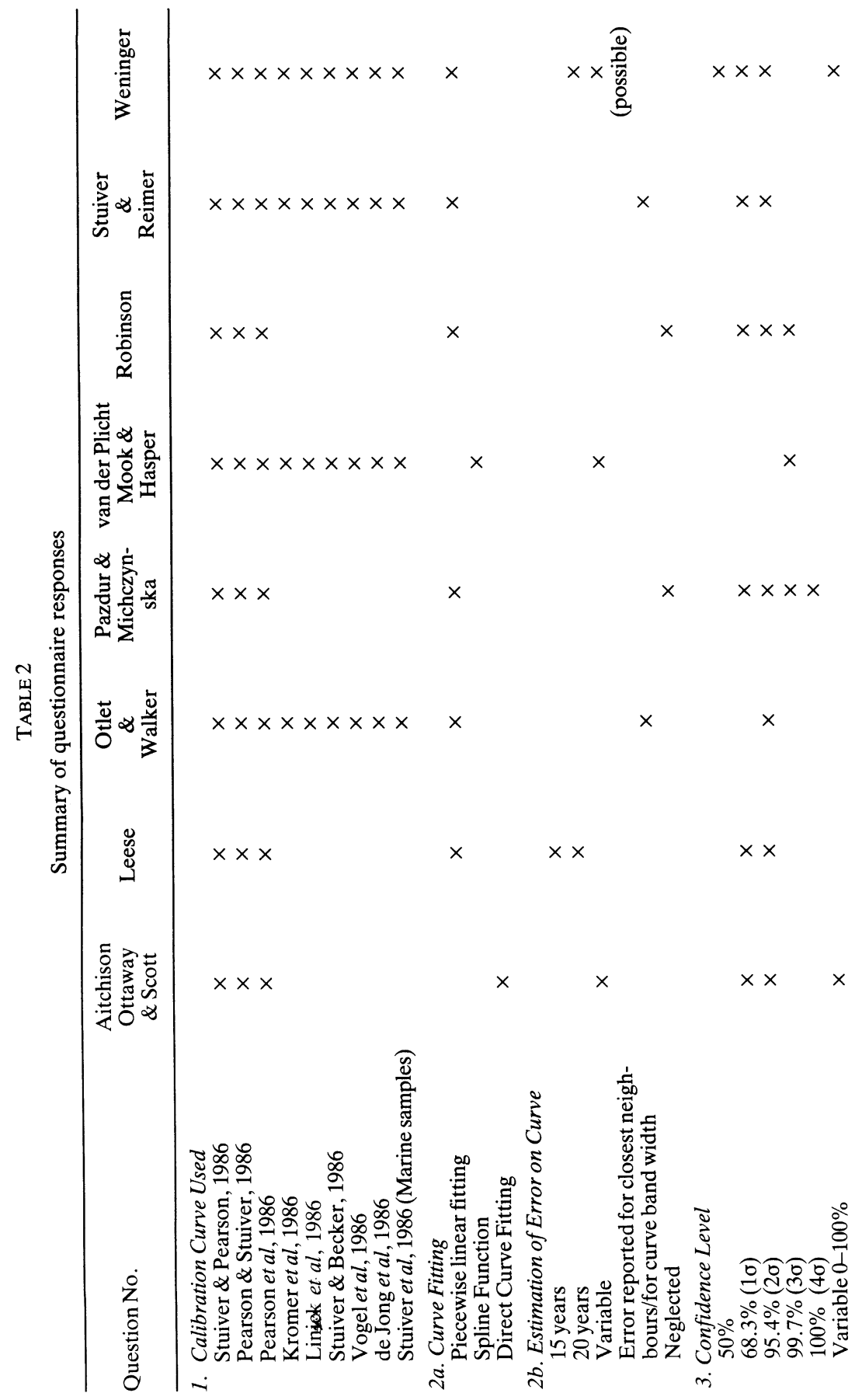




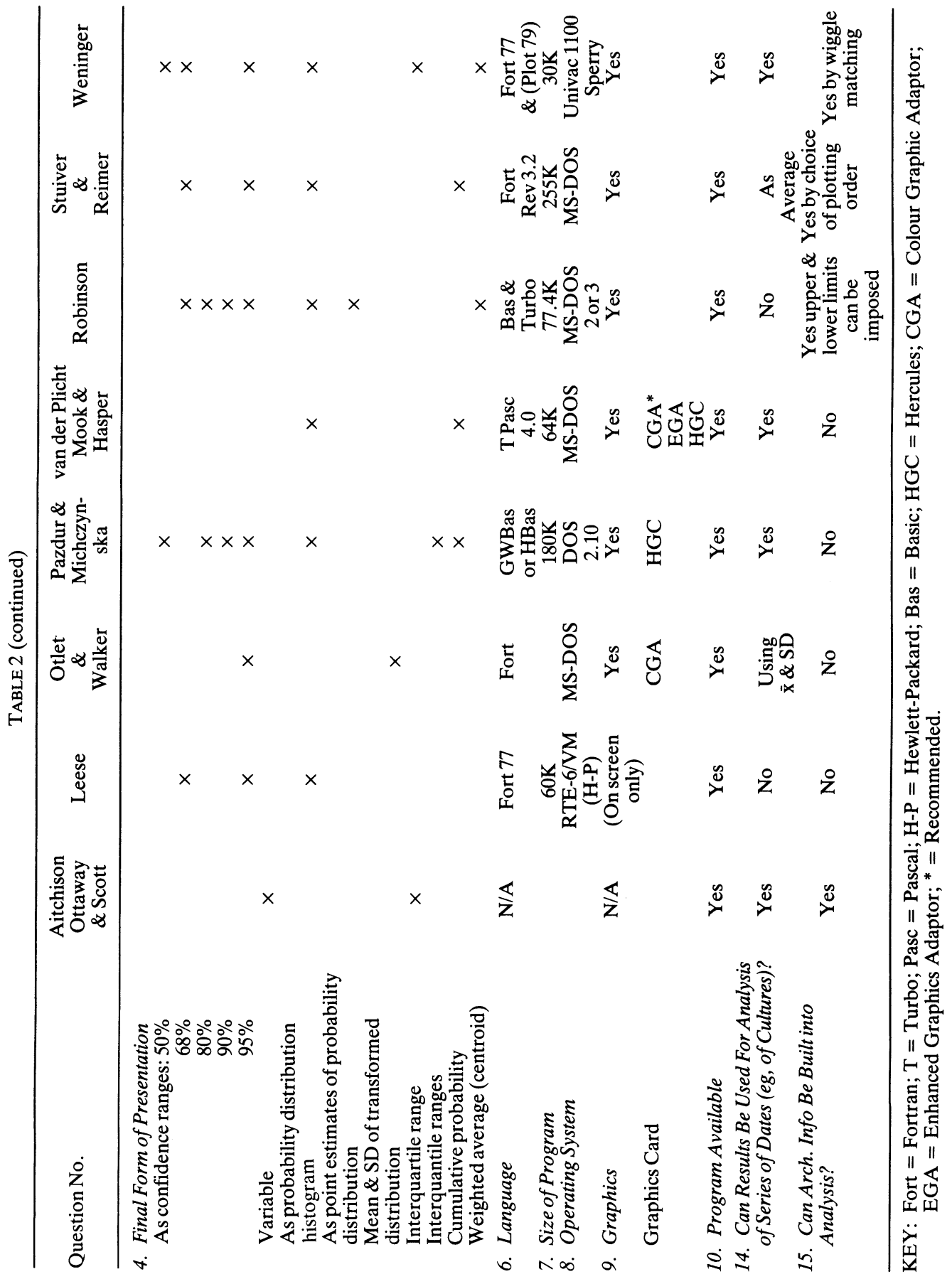


TABLE 3

Sample output for a single date from all participants

Values quoted by groups for calibrated ages of date A3: GrN-6483:4790 \pm 40 BP

Leese (cf Fig 1)

$68 \%$ confidence limits (CL) estimated from histogram (bin size 10yr) (results for $95 \% \mathrm{CL}$ also provided)

$\begin{array}{ccc}\text { Limits } & \text { (cal BC) } & \text { Rel freq } \\ 5470 & 3520 & \\ 5500 & 3550 & 18 \% \\ 5520 & 3570 & \\ 5530 & 3580 & 8 \% \\ & & \\ 5560 & 3610 & \\ 5600 & 3650 & 41 \% \\ \text { Total } & & 67 \%\end{array}$

$\begin{array}{ll}\text { Otlet (cf Fig 2) } & \\ & \text { Calibrated date } \\ 95 \% \text { range } & \text { Mean and SD } \\ 3695-3383 \text { cal BC } & 3572 \pm 73 \text { cal BC }\end{array}$

\section{Pazdur (cf Fig 3)}

Max probability (P) for dates: 5518, 5490, 5576, 5340

Interval of cal age: $(5322,5658)(5695,5726)$

\begin{tabular}{cccr}
$\mathrm{P}(\mathrm{T}<$ to $)$ & To cal BP & \multicolumn{2}{c}{ Ranges: } \\
0.01 & 5338 & 0.50 & $(5491,5570)$ \\
0.05 & 5452 & 0.95 & $(5345,5627)$ \\
0.10 & 5471 & 0.98 & $(5338,5636)$ \\
0.25 & 5491 & & \\
0.50 & 5521 & & \\
0.75 & 5570 & & \\
0.90 & 5591 & & \\
0.95 & 5615 & & \\
0.99 & 5636 & &
\end{tabular}

van dër Plicht, Mook \& Hasper

The following is how the users are told, by instructions that come with the program, to analyze the graphs. The results cannot be printed out automatically, since there are no general algorithm which fit all cases. For this reason, the results are presented in graphic form.

Calibrated results in terms of $16 / 50 / 84 \%$ probability

$\begin{array}{ll}50 \% \mathrm{P}(\text { median }) & : 3567 \mathrm{cal} \mathrm{BC} \\ 84 \% \mathrm{P} & : 3526 \mathrm{cal} \mathrm{BC} \\ 16 \% \mathrm{P} & : 3629 \mathrm{cal} \mathrm{BC}\end{array}$


Ranges and Probabilities

TABLE 3 (Continued)

$\begin{array}{lr}3375-3410 \text { cal BC } & 6 \% \\ 3505-3595 \text { cal BC } & 57 \% \\ 3595-3655 \text { cal BC } & 30 \% \\ 3655-3695 \text { cal BC } & 7 \%\end{array}$

$3655-3695 \mathrm{cal} \mathrm{BC}$

Robinson (cf Fig 4)

Cal-Centroid $=-3585 \pm 61$

$68 \% \mathrm{CL}=-3648$ to -3542

$80 \% \mathrm{CL}=-3657$ to -3533

$90 \% \mathrm{CL}=-3667$ to -3513

$95 \% \mathrm{CL}=-3693$ to -3404

Stuiver \& Reimer ( $c f$ Fig 5)

Calibrated age(s) -BC: $3626,3568,3540$ -BP: $5575,5517,5489$

cal $\mathrm{AD} / \mathrm{BC}$ (cal BP) age ranges obtained from intercepts (Method A)

$1 \sigma^{* *}$ cal вС 3641-3607 (5590-5556) 3584-3520 (5533-5469)

$2 \sigma^{* *}$ cal BC 3694-3503 (5643-5452) 3407-3384 (5356-5333)

Summary of above

Min of cal age ranges (cal ages), max of cal age ranges:

$1 \sigma \mathrm{cal}$ BC $3641(3626,3568,3540) 3520$

cal вP $5590(5575,5517,5489) 5469$

$2 \sigma$ cal BC $3694(3626,3568,3540) 3384$

cal BP $5643(5575,5517,5489) 5333$

cal $\mathrm{AD} / \mathrm{BC}$ age ranges (cal ages as above) from probability distribution (Method $\mathrm{B}$ )

$\%$ area enclosed cal BC (cal BP) age ranges

$68.3(1 \sigma)$

cal BC 3642-3605 (5591-5554)

relative area under

$95.4(2 \sigma)$

$3585-3519(5534-5468)$

cal BC 3692-3505 (5641-5454)

3403-3385 (5352-5334)

relative area under
probability distribution

Aitchison, Ottaway \& Scott (cf Fig 6)

Since the Pearson \& Stuiver curves are in the form of calibration curve \pm one standard error on the curve intersecting such curves with ${ }^{14} \mathrm{C}$ date $\pm \mathrm{k}^{*}$, quoted error on the date will give appropriate confidence intervals, eg, $\mathrm{k}=0.71$ gives $\sim 68 \%$ confidence while $\mathrm{k}=1.77$ gives $\sim 95 \%$ confidence.

- $68 \%$ confidence interval is $3640-3520$ cal BC

- $95 \%$ confidence interval is $3700-3505$ cal BC 3420-3390 cal BC

Weninger

Non-normalized dates

$95 \%$ Peak center is $3671 \mathrm{BC}-3385 \mathrm{BC}$

$68 \%$ Peak center is $3619 \mathrm{BC}-3505 \mathrm{BC}$

$50 \%$ Peak center is $3601 \mathrm{BC}-3525 \mathrm{BC}$

Normalized dates:

$95 \%$ Peak center is $3682 \mathrm{BC}-3406 \mathrm{BC}$

$68 \%$ Peak center is $3617 \mathrm{BC}-3505 \mathrm{BC}$

$50 \%$ Peak center is $3596 \mathrm{BC}-3521 \mathrm{BC}$ 


\section{RESULTS}

This report does not indicate final results; it is very much a working report and provides an initial interpretation of general findings. Critical comments are quite incomplete.

A summary of the questionnaire can be found in Table 2. The first three questions give technical calibration details.

All groups provide some form of printout of the results (Table 2.4). We

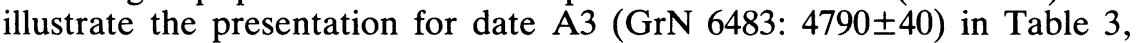
which also demonstrates the different approaches. However, the graphic output best illustrates the underlying philosophy. Using date A3, Leese (Fig 1) gives a histogram showing the distribution of the calibrated values. Otlet (Fig 2) reproduces the appropriate part of the calibration curve and presents the results as a probability distribution quoting its mean and standard deviation (SD). He also gives the $95 \%$ confidence range but this is obtained directly from the \pm 2 SD limits of the ${ }^{14} \mathrm{C}$ determination, taking the widest intercepts given by the curve band width at each end of the range. Pazdur (Fig 3) plots the initial probability distribution of the conventional ${ }^{14} \mathrm{C}$ age, together with the appropriate part of the calibration curve and the resulting probability distribution of the calibrated age. He then gives a second graph where the same probability distribution as in Figure 3 is shown together with the cumulative distribution function of the calibrated age. (Note: Pazdur plans to adjust these graphs slightly to improve presentation).

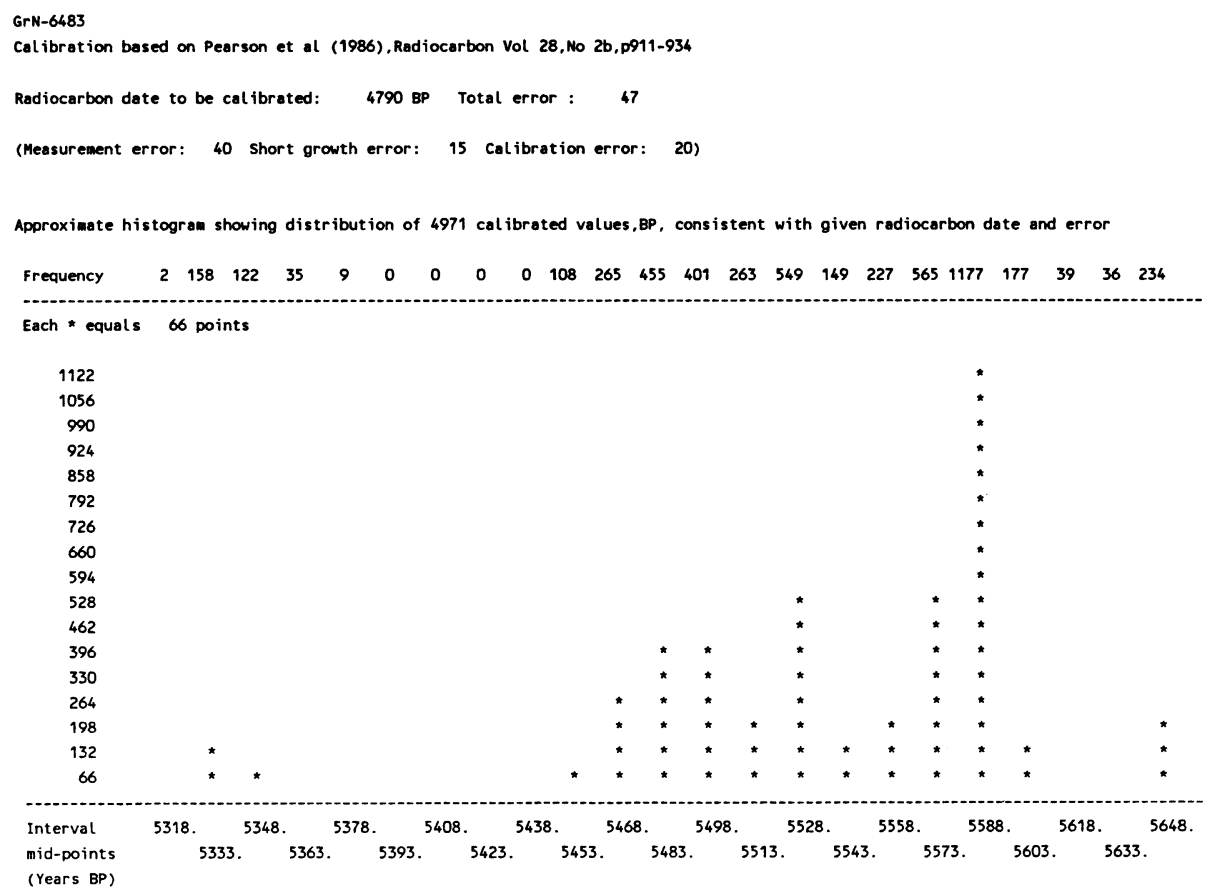




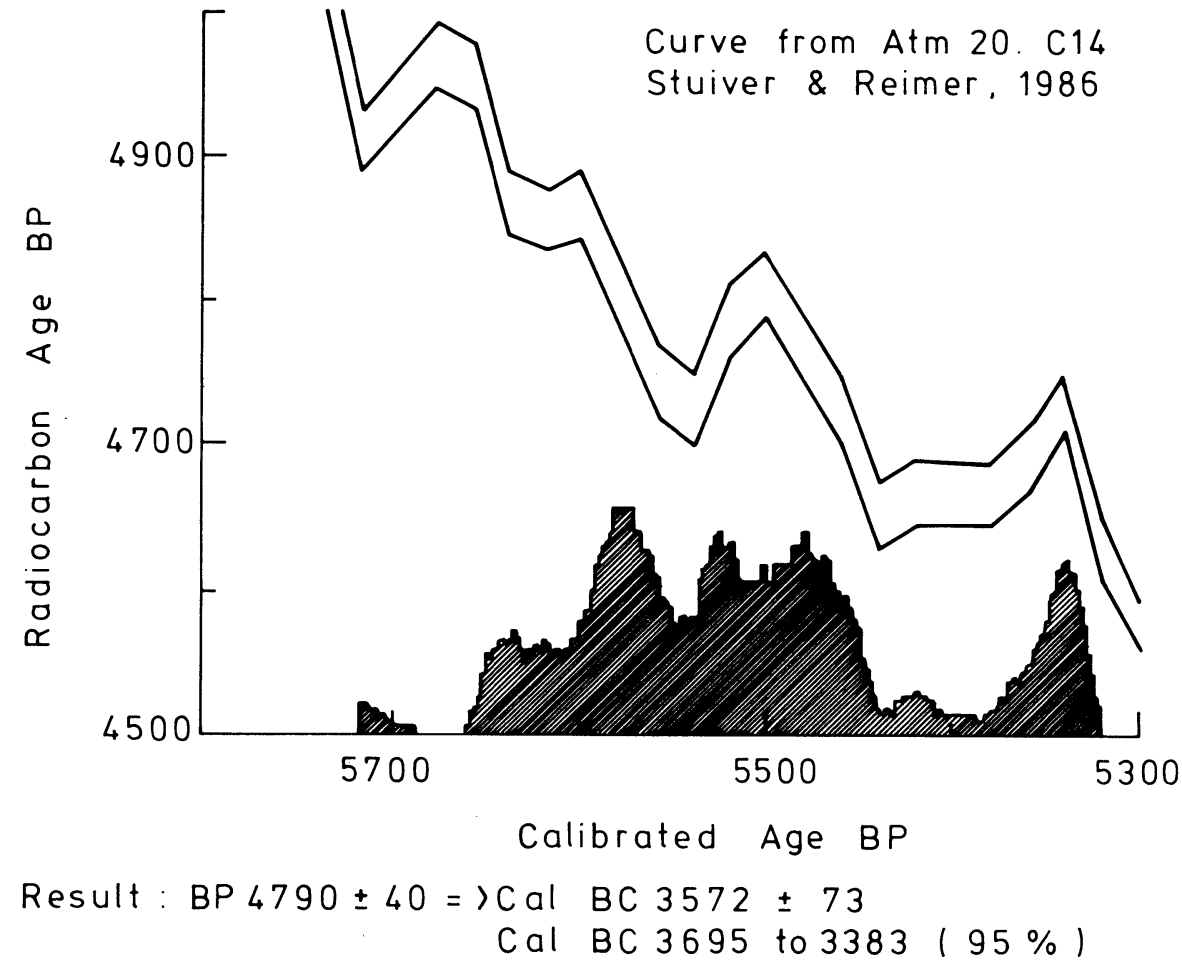

Fig 2. Graphic output for date A3 (Otlet)
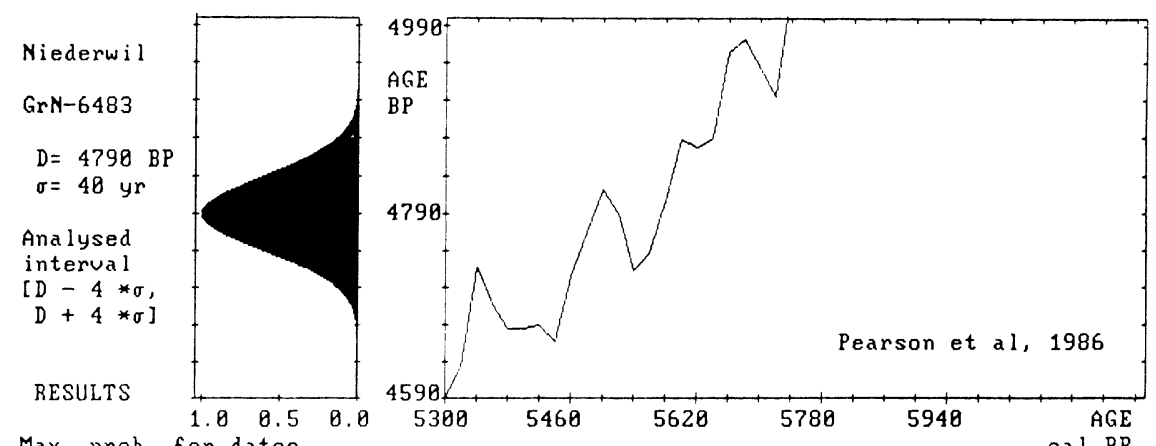

Max. prob. for dates

$5518,5490,5576,5340$

Intervals of cal age:

[ 5322,5658$][5695,5726]$ Ranges

$\begin{array}{ll}0.50 & (5491,5570) \\ 0.95 & (5345,5627) \\ 0.98 & (5338,5636)\end{array}$

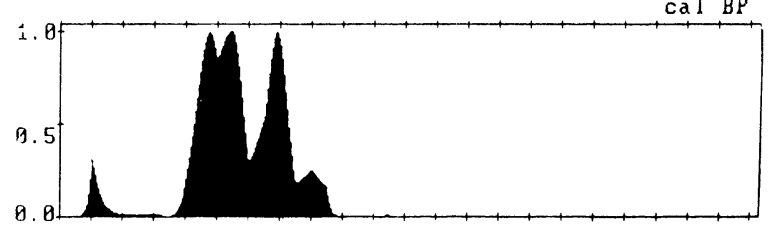

Fig 3. Graphic output for date A3 (Pazdur et al) 
Van der Plicht, Mook and Hasper also plot the probability distribution of the ${ }^{14} \mathrm{C}$ age and that of the calibrated age together with the relevant part of the calibration curve all on one graph. The same probability distribution is printed out on a second graph together with the cumulative probability. Thus, the approaches of Pazdur and van der Plicht are almost identical. The Groningen code has now been upgraded to include a third graph with the same calibrated probability distribution, analyzed at 68.3 and $95.4 \%$ confidence levels. The corresponding age ranges are printed out. (For more details, see van der Plicht \& Mook, this issue).

Robinson's (Fig 4) graphic printout shows the probability distribution, in histogram form, of the calibrated age, with the relevant part of the calibration curve and indicates the point estimate computed as the centroid of the probability distribution. Stuiver and Reimer show the probability distribution indicating multiple ranges with the percent of the area under the curve for each range (Fig 5). Weninger plots the normalized and non-normalized probability distribution of the ${ }^{14} \mathrm{C}$ age and of the resulting calibrated age.

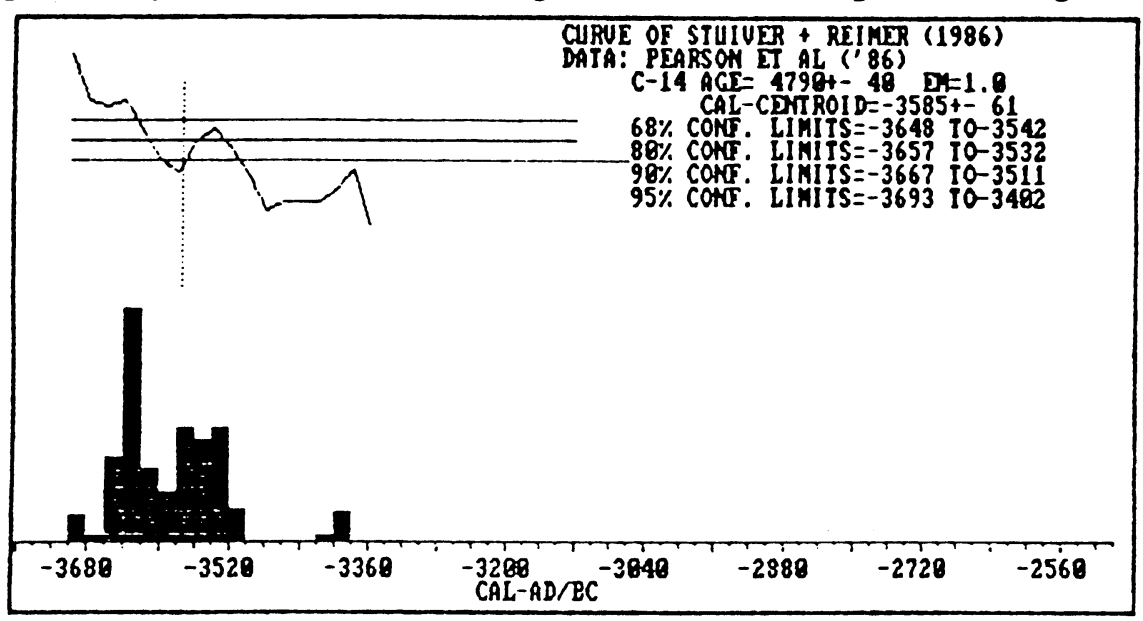

Fig 4. Graphic output for date A3 (Robinson)

Finally, Aitchison, Ottaway and Scott use the graphs from Pearson et al (1986) (Fig 6) to provide an appropriate confidence interval for the calibrated age with the width of the interval about the ${ }^{14} \mathrm{C}$ age determining the confidence probability. This method (Aitchison \& Scott, 1987) requires no computing and can be carried out directly from the appropriate graph.

The underlying theory behind the calibration methods cannot be discussed in detail here. In summary, the approach of van der Plicht, Mook and Hasper (in press) is very close to that of Michczynska, Pazdur and Walanus (in press). Stuiver and Reimer's (1986) approach is somewhat similar to that of Leese (1988). Robinson (1986) ends up with only one range by excluding a percentage from either end of the calibrated distribution. Aitchison, Ottaway and Scott (in press) follow Ottaway's (1972) earlier simple approach. Otlet (pers commun) and Weninger $(1986,1987)$ have more individual styles. 


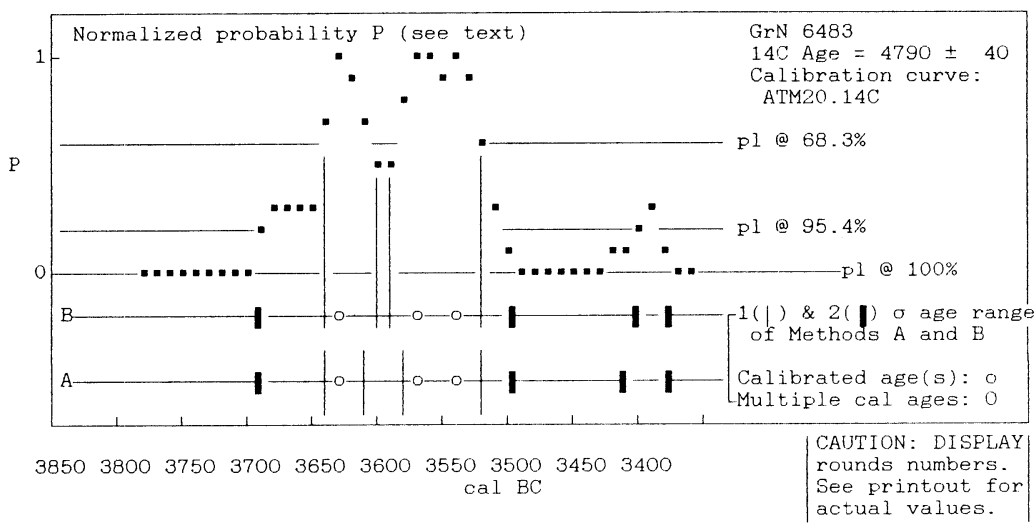

Fig 5. Graphic output for date A3 (Stuiver \& Reimer)

There is a basic philosophical question about whether or not the probability associated with a particular ${ }^{14} \mathrm{C}$ activity within the total span should be divided between the several alternative real dates representing that activity. Reimer and Stuiver, Warner and Weninger think it should be divided, whereas van der Plicht and Pazdur do not. R Warner (pers commun) feels that until the underlying philosophy of that question is resolved, only range calibrations should be used. This opinion was not shared by most of the authors.

In an effort to compare directly the results of all the groups,we plotted the $68 \%$ confidence intervals of the calibrated ages in data set $\mathrm{A}$ as bars (Fig 7) (except Otlet \& Walker, where the bar length is the range of $\pm 1 \sigma$ of the transformed distribution).

Four of the 8 groups did not calibrate date A1 (7030 $\pm 80 \mathrm{BP})$, since it was outside the range of Pearson et al's curve. Results of all four groups (Fig 7.1) showed remarkable agreement; the largest variation is $29 \mathrm{yr}$ on the upper part of the scale and 47 on the lower part. Date A2 (Fig 7.2) had a very large error $( \pm 140 \mathrm{yr})$. Consequently, the calibrated age intervals span $300-500 \mathrm{yr}$ and agreement was poor. Two groups were unable to calibrate this date, since the $99.7 \%$ range BP took them outside the limits of the present calibration curve.

Agreement on the calibrated age ranges of data A3 \& A4 (Fig 7.3, 7.4) is excellent and does not vary more than a maximal $30 \mathrm{yr}$ at either end of the

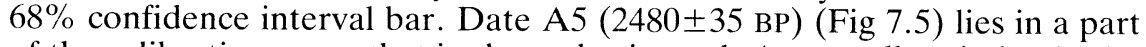
of the calibration curve that is almost horizontal. Any small variation in the treatment of the error will thus be more noticeable, leading to a greater variation in the resulting calibrated age intervals. Consequently, the intervals vary by as much as 60 and $120 \mathrm{yr}$, respectively, at the upper and lower part of the cal BC scale. Date A6 (Fig 7.6) again shows good agreement among the eight groups.

Thus, comparing the $68 \%$ confidence intervals for the individual dates in Data Set A, we find an overall agreement of the results. If we were to consider the scientifically more acceptable $95.7 \%$ confidence intervals, 
oal BP

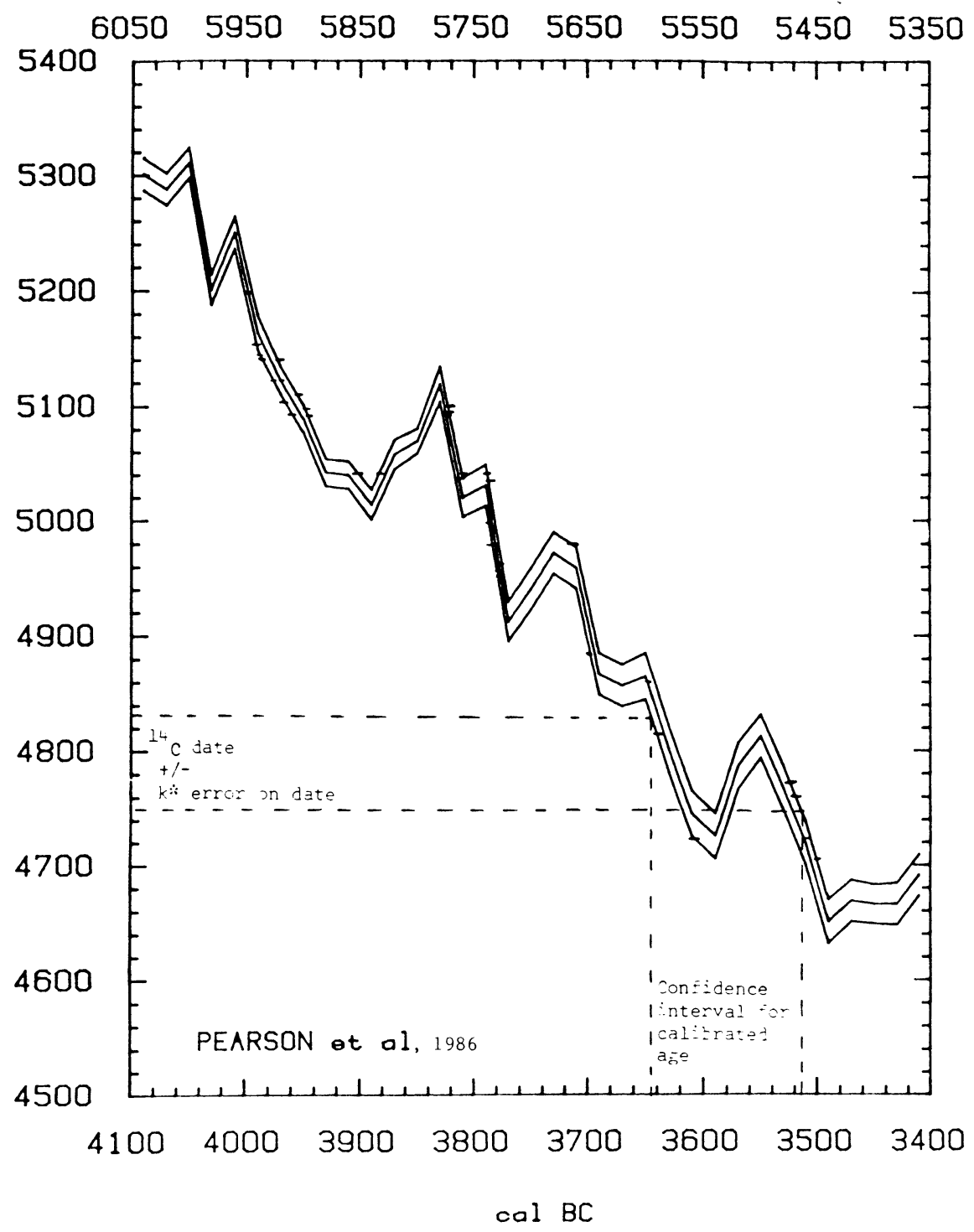

Fig 6. Graphic output for date A3 (Aitchison et al) 


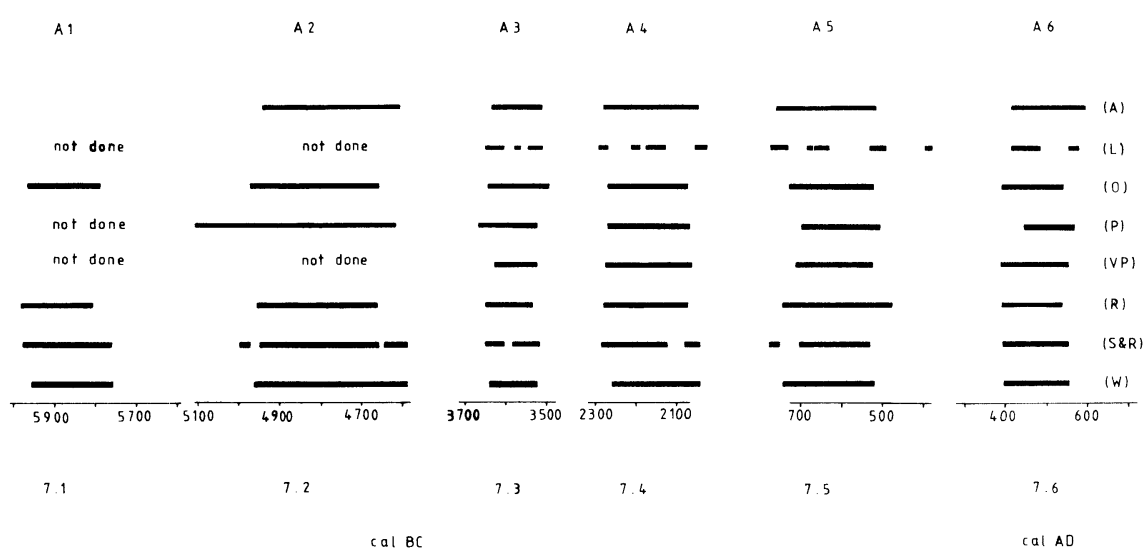

Fig 7. Summary of results for A3 (at $68 \%$ confidence): A - Aitchison et al $;$ L - Leese; $\mathrm{O}$ - Otlet; P - Pazdur; VP - van der Plicht et al; R - Robinson; S \& R - Stuiver \& Reimer; W - Weninger

agreement is even better and the disjoint intervals merge into one continuous line.

Most of the eight groups used different methods of calibrating identical samples dated by different laboratories (Table 1, C1) and of counting replicates of homogenized samples $(\mathrm{C} 2.1, \mathrm{C} 2.2)$. Most groups calculated either the weighted mean or the average of all dates in one batch before calibration (Robinson did this, although he did not actually give the results for these two groups of dates), thus achieving a better estimate of the true age. Two groups did not do this; their calibrated age spread over ca $250 \mathrm{yr}$ (Fig 8). Thus, when dealing with truly replicate dates, a common approach would be very desirable to ensure comparable results.
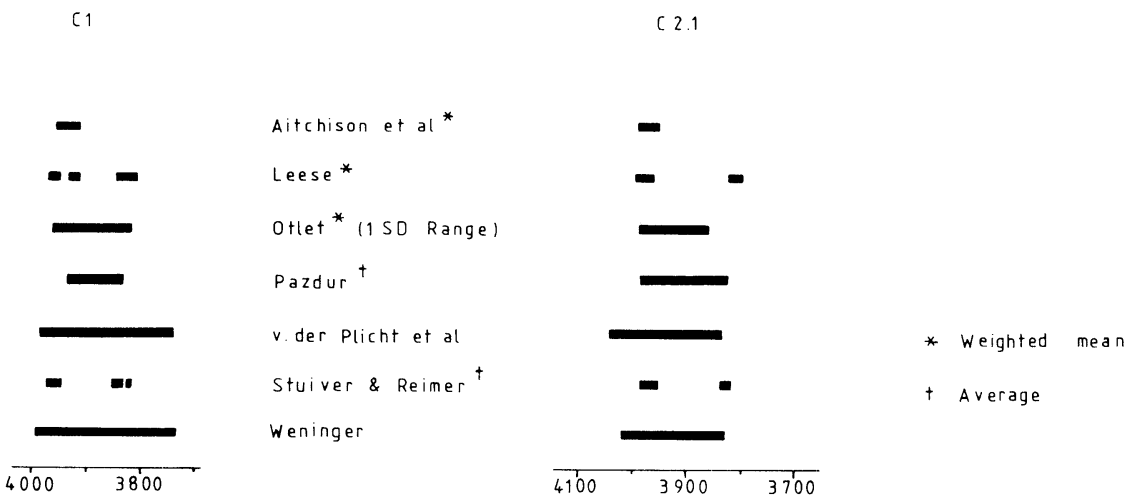

cal $B C$

Fig 8. Summary of results for data $\mathrm{C} 1$ and $\mathrm{C} 2.1$ - homogenized replicates (at $68 \%$ confidence) 
Thus, we have agreement on calibrating single dates, ie, the intervals are approximately the same width. Stuiver, Reimer and Leese's results gave disjoint intervals. The van der Plicht et al, Pazdur and Stuiver and Reimer results have the added advantage of giving probabilities to each of the peaks within the calibrated interval.

There is also agreement on treatment of replicate dates, dating the same artifact, which after calculation of the weighted mean and SD, should be treated as a single value. Calculation of the weighted mean and its accompanying new standard deviation is only advised if the dates are genuine replicates, ie, the same object/sample. It is NOT advised for dates of material from one archaeological layer, context or horizon of dates.

Groups B1-B4 (Table 1) were included to deal with the problem of noncontemporaneous dates. These would be used to quantify duration of time and when combined with other data, might answer questions of contemporaneity of cultures.

Pazdur \& Michczynska (1989), van der Plicht, (1988), Weninger (1987) and Aitchison, Ottaway and Scott (in press), have developed methods for calibrating such dates. The latter three authors felt that the comparison of the methods should be based on a single archaeologically meaningful quantity. The floruit (Ottaway, 1972), the period over which the middle $50 \%$ of all the culture's datable artifacts were produced, was chosen. Figure 9 shows the floruit and its mathematical definition: the period between the two quar-

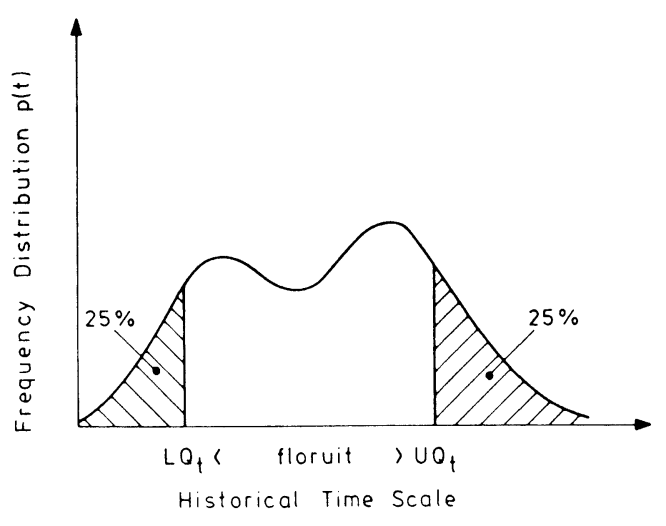

Fig 9. Graphic representation of a floruit

tiles of the frequency distribution of the culture's artifacts. A major assumption underlies our use of the sampled dates to estimate the floruit, namely, that the artifact sampling process provides us with a representative sample of the entire population of cultural artifacts.

Table 4 shows results of four groups of dates. Some participants did not return estimates of the floruit and point estimates had to be derived from the supplied information. In addition, Aitchison et al provided interval estimates for the floruit. Details of this approach are to appear soon. 
TABLE 4

Results submitted for groups of non-contemporaneous ${ }^{14} \mathrm{C}$ dates

\begin{tabular}{|c|c|c|c|c|c|}
\hline \multicolumn{6}{|c|}{ A. Point estimates of the floruit } \\
\hline & & Weninger & Pazdur & Aitchison & van der Plicht \\
\hline \multirow{4}{*}{ Group } & $\mathrm{B}_{1}$ & $4325-4009$ & $4318-4056$ & $4320-3925$ & - \\
\hline & $\mathbf{B}_{2}$ & $4132-3947$ & $4130-3994$ & $4030-3980$ & $4140-3960$ \\
\hline & $\mathrm{B}_{3}$ & $3743-3529$ & $3757-3520$ & $3770-3560$ & $3760-3550$ \\
\hline & $\mathrm{B}_{4}$ & $3054-2748$ & $3000-2723$ & $3010-2810$ & $3020-2800$ \\
\hline
\end{tabular}

B. Interval estimates of the floruit (provided by Aitchison et al)

\begin{tabular}{llll}
\hline \multirow{6}{*}{ Group } & $\mathrm{B}_{1}$ & 4400 & 3780 \\
$\mathrm{~B}_{2}$ & 4045 & 3955 \\
& $\mathrm{~B}_{3}$ & 3800 & 3500 \\
$\mathrm{~B}_{4}$ & 3075 & 2760 \\
\hline
\end{tabular}

Resulting estimates are shown in Figure 10. Some differences in the results are apparent, particularly for series B2, which is due, in part, to a very small wiggle at the limit of the calibration limits for this series.

It is clear that further work is necessary in this area of archaeological interest to make available the techniques necessary to construct interval estimates for the floruit as well as to clarify and use the cultural frequency distribution.

\section{CONCLUSIONS}

In comparing eight methods of calibrating ${ }^{14} \mathrm{C}$ dates, we found reasonably good agreement between the methods in calibrating single dates. Genuine replicate dates gave equally good agreement, after calculation of the weighted mean and standard deviation and subsequent treatment as single dates. Series of ${ }^{14} \mathrm{C}$ dates pertaining to the duration of a period could only be meaningfully handled by four groups.

Further calibration work is needed to ensure a sound methodological base to deal with the remaining procedural and interpretational problems.

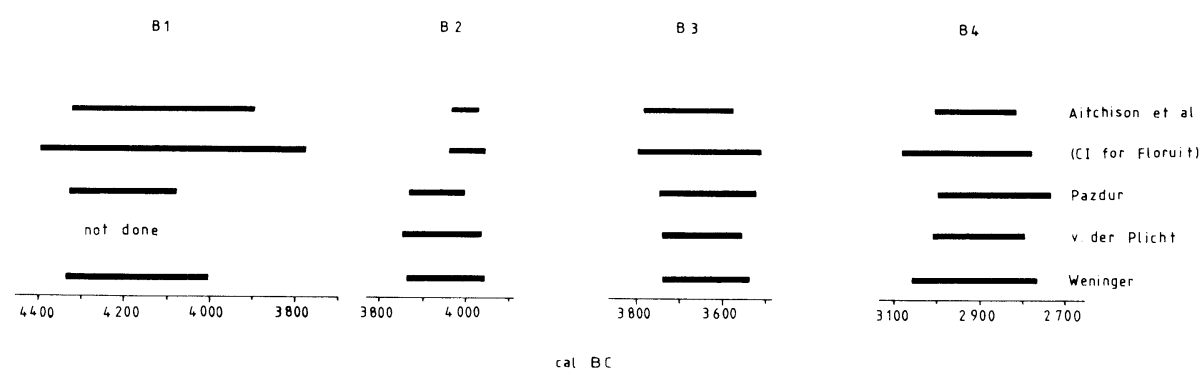

Fig 10. Presentation of results at $68 \%$ confidence for data sets B1-B4 
Many of the methods described here are being developed further. Stuiver and Reimer's program will be revised to include Aitchison et al's strategy for series of dates and the calculation of weighted mean and standard deviation. Layouts and graphics will also be improved.

The general recommendation for presentation of calibrated dates from the ${ }^{14} \mathrm{C}$ laboratories to the archaeological users is a combination of graphs and ranges. The use of quoting a calibrated age as a mean and SD is recommended only if the graph on the absolute time scale shows an approximately Gaussian distribution.

\section{REFERENCES}

Aitchison, T C, Ottaway, B S and Scott, E M, in press, Statistical treatment of groups of related radiocarbon dates, in Internatl symposium on archaeology and ${ }^{14} \mathrm{C}, 2$ nd: PACT.

Aitchison, T C and Scott, E M, 1987, A review of the methodology for calibrating radiocarbon dates into historical ages: BAR internatl ser 333, p 187-201.

de Jong, A F M, Becker, B and Mook, W G, 1986, High-precision calibration of the radiocarbon time scale, 3930-3230 cal BC, in Stuiver, $\mathrm{M}$ and Kra, R S, eds, Internat ${ }^{14} \mathrm{C}$ conf, 12 th, Proc: Radiocarbon, v 28, no. 2B, p 939-942.

International Study Group, 1982, An interlaboratory comparison of radiocarbon measurements in tree-rings: Nature, v 298, p 619-623.

Kromer, B, Rhein, M, Bruns, M, Schoch-Fischer, H, Münnich, K O, Stuiver, M and Becker, B, 1986, Radiocarbon calibration data for the 6th to 8th millennia BC, in Stuiver, M and Kra, R S, eds, Internatl ${ }^{14} \mathrm{C}$ conf, 12th, Proc: Radiocarbon, v 28, no. 2B, p 954-960.

Lanting, J N and Mook, W G, 1977, The prehistory of the Netherlands in terms of radiocarbon dates: Groningen, Groningen Univ Press.

Leese, M N, 1988, Methods for finding calendar date bands from multiple-valued radiocarbon calibration curves, in Ruggles, C L N and Rahtz, S P Q, eds, Computer and quantitative methods in archaeology: BAR internatl ser 393, p 147-151.

Michczynska, D J, Pazdur, M F and Walanus, A, in press, Bayesian approach to probabilistic calibration of radiocarbon dates, in Internatl syposium on archaeology and ${ }^{14} \mathrm{C}$ : PACT.

Ottaway, B S, 1972, Dispersion diagrams: a new approach to the display of ${ }^{14} \mathrm{C}$ dates: Archaeometry, v 15, p 5-12.

1986, Neue Radiokarbondaten Altheimer und Chamer Siedlungsplätze in Niederbayern: Archaeol Korrespondenzblatt, v 16, p 141-147.

Pazdur, M F and Michczynska, D J, 1989, Improvement of the procedure for probabilistic calibration of radiocarbon dates: Radiocarbon, this issue.

Pearson, G W and Stuiver, M, 1986, High-precision calibration of the radiocarbon time scale $500-2500 \mathrm{BC}$, in Stuiver, M and Kra, R S, eds, Internatl ${ }^{14} \mathrm{C}$ conf, 12 th, Proc: Radiocarbon, v 28 , no. 2 B, p 839-862.

Pearson, G W, Pilcher, J R, Baillie, M G L B, Corbett, D M and Qua, F, 1986, High-precision ${ }^{14} \mathrm{C}$ measurement of Irish oak to show the natural ${ }^{14} \mathrm{C}$ variation from $\mathrm{AD} 1840-5210 \mathrm{BC}$, in Stuiver, $\mathrm{M}$ and Kra, R S, eds, Internatl ${ }^{14} \mathrm{C}$ conf, 12th, Proc: Radiocarbon, v 28, no. 2B, p 911-934.

Robinson, S W, (ms) 1986, A computational procedure for the utilization of high-precision radiocarbon calibration curves: Open-file rept, USGS.

Scott, E M, Baxter, M S and Aitchison, T C, 1983, An assessment of variability in radiocarbon dating, in Methods of low level counting and spectrometry: IAEA, Berlin, p 371-392.

Stuiver, M and Becker, B, 1986, High-precision decadal calibration of radiocarbon time scale, AD 1950-2500, in Stuiver, M and Kra, R S, eds, Internat ${ }^{14} \mathrm{C}$ conf, 12 th, Proc: Radiocarbon, v 28 , no. 2B, p 863-910.

Stuiver, M and Pearson, G W, 1986, High-precision calibration of the radiocarbon time scale, AD $1950-500 \mathrm{BC}$, in Stuiver, M and Kra, R S, eds, Internatl ${ }^{14} \mathrm{C}$ conf, 12 th, Proc: Radiocarbon, $v 28$, no. 2B, p 805-838.

Stuiver, M, Pearson, G W and Braziunas, T F, 1986, Radiocarbon age calibration of marine samples back to $9000 \mathrm{cal}$ yr BP, in Stuiver, $\mathrm{M}$ and $\mathrm{Kra}, \mathrm{R} \mathrm{S}$, eds, Internatl ${ }^{14} \mathrm{C}$ conf, $12 \mathrm{th}$, Proc: Radiocarbon, v 28, no. 2B, p 980-1021.

Stuiver, M and Reimer, P, 1986, A computer program for radiocarbon age calibration, in Stuiver, $\mathrm{M}$ and Kra, R S, eds, Internatl ${ }^{14} \mathrm{C}$ conf, 12 th, Proc: Radiocarbon, $v 28$, no. $2 \mathrm{~B}, \mathrm{p}$ $1022-1030$. 
van der Plicht, J, Mook, W G and Hasper, H, in press, Automatic calibration of radiocarbon dates, in Internatl symposium Archaeology and ${ }^{14} \mathrm{C}$ : PACT.

Vogel, J C, Fuls, A and Visser, E, 1986, Radiocarbon fluctuations during the third millennium $\mathrm{BC}$, in Stuiver, $\mathrm{M}$ and Kra, R S, eds, Internatl ${ }^{14} \mathrm{C}$ conf, 12th, Proc: Radiocarbon, v 28, no. 2B, p 935-938.

Weninger, B, 1986, High-precision calibration of archaeological radiocarbon dates: Acta Interdisciplinaria Archaeol, IV, Nitra, p 11-53.

Zabern, p 4-13 


\section{APPLICATIONS}
A. Hydrology
B. Geochronology and Paleoclimatology
C. Archaeology and Material Culture
D. Radiocarbon Data Base 